\title{
A Administração de Pessoal e a Burocracia na Itália
}

GIORGIO PASTORI

Professor da Universidade de Milão TRADUÇÃO DE ARAÚJO CAVALCANTI

NOTA PRÉ'JIA DO TRADUTOR

O Instituto Internacional de Ciências Administrativas promove, com regularidade e eficiência, a divulgação de estudos e informações de reconhecida categoria educativa ou técnica, a respeito dos problemas de govêrno e administração dos países mais desenvolvidos, através da sua International Review of Administrative Sciences, editada em Bruxelas, na Bélgica, e que circula em três idiomas - inglês, francês e espanhol.

Assim é que, como decorrência do XV Congresso Internacional de Ciências Administrativas, recentemente levado a efeito em Roma, de 6 a 11 de setembro de 1971 , o Volume XXXVII, n?s $1 / 2$, daquela conceituada Revista, foi inteiramente dedicado à Itália.

Não poderia a Revista do Serviço Público deixar de registrar a realização do importante Congresso - do qual participou, aliás, o Brasil, que é um dos membros mais atuantes do Instituto Internacional de Ciências Administrativas, cuja Seção Nacional, em nosso País, é presidida, no momento, pelo Dr. Luís Simões Lopes, atual Presidente da Fundaçăo Getúlio Vargas.

Evidentemente não seria possivel traduzir, em sua totalidade, o conjunto dos principais artigos selecionados pelo Instituto Internacional de Ciências Administrativas. Contudo, a Revista do Serviço Público escolheu "A Administração de Pessoal e a Burocracia na Itália", de autoria do consagrado Professor universitário GIORGIO PASTORI, de Milão, em virtude das autorizadas informaçōes contidas no aludido trabalho a respeito de assuntos de real interêsse para o serviço público no campo da administração de pessoal, não sòmente para a Itália como para os países em processo de desenvolvimento.

Os dirigentes do serviço público brasileiro terão, certamente, justificada curiosidade no conhecimento da situa-

Fonte: International Review of Administrative Sciences. Volume XXXVII, n. ${ }^{\circ} 1-2$, setembro de 1971. (Número especial dedicado ao XV Congresso Internacional de Ciênclas Administrativas, realizado em Roma, em agôsto de 1971. 
ção e tendências da administração pública da Itália para um cotejo ou análise comparativa. Ninguém ignora a profunda influência mundial do pensamento jurídico italiano, notadamente no tocante à problemática do Direito Administrativo. Mas, igualmente importante tem sido, depois da Segunda Guerra Mundial, o extraordinário desenvolvimento das ciências administrativas na Itália que vem mantendo, com êxito integral, La Scienza e la Tecnica della Organizzazzione nella Pubblica Amministrazione justamente considerada como uma das melhores publicações de nossa época, em todo o mundo, no campo das mencionadas clências.

As principais universidades italianas dedicam parte considerável de seus esforços e recursos à pesquisa, estudo e ensino do Direito Administrativo e das disciplinas integrantes do complexo das ciências administrativas. Essa é uma das características da Itália moderna: o desenvolvimento simultâneo e equilibrado das ciências jurídicas e das ciências administrativas.

A Escola de Aperfeiçoamento em Ciências Administrativas da Universidade de Bolonha, por exemplo, instituiu, como o faz todos os anos, o curso bienal de estudos administrativos que proporciona formação técnica necessária aos que desejam exercer cargos de direção tanto no setor público como no setor privado, ou então desempenhar funções especiais no âmbito do ensino e pesquisa aplicada.

O curso é de nível superior, consagrando-se o primeiro ano a um ensino de base comum: principios constitucionais e administrativos italianos; contabilidade pública; programação e orçamento; política econômica; econo- mia de mercado; administração de pessoal; organização da Comunidade Européia - Mercado Comum Europeu (MCE); elementos de estatística aplicada; elementos de ciência da administração.

No decorrer do segundo ano, os estudantes se dividem em duas áreas de especialização e seguem os seguintes cursos:

1) especialização técnica: sociologia aplicada; psicologia aplicada; ciências da administração; teoria da organização; técnicas de organização; técnicas de seleção e avaliação de pessoal; análise quantitativa e pesquisa operacional; metodologia de pesquisa.

2) Especialização jurídica: direito administrativo especial; organização jurídica dos podêres locais; justiça administrativa; emprêsas públicas; direito público da economia; direito sindical e relações industriais; direito da $\mathrm{CO}^{-}$ munidade Européia.

Cada estudante, independentemente dos exames orais obrigatórios, deve apresentar uma monografia no fim do curso, ao ensejo do encerramento das aulas.

É de se ressaltar, na experiência italiana de formação, treinamento, especialização e aperfeiçoamento dos servidores públicos, a influência pioneira das diretrizes da Escola Nacional de Administração (francesa) que, por sua vez, inspirou, em suas grandes linhas de orientação técnico-pedagógica, a Escola Superior de Ciências Administrativas de Speyer (Alemanha). Destarte, a Itália, a França e a Alemanha implantaram uma política convergente e semelhante na órbita do aperfeiçoamento do pessoal. 
A Revista do Serviço Público chama a atenção dos seus leitores para os seguintes trabalhos que enriquecem o Volume XXXVII/1971, nos 1-2, da International Review of Administrative Sciences, densos de substância técnico-cultural e oportunidade, proporcionam uma visão clara e objetiva do panorama da Itália no concernente ao aggiornamento de sua administraçăo:

- Tendências no desenvolvimento das ciências administrativas na Itália - Massimo Gianninni, da Universidade de Roma;

- As tendências de transformação da administração italiana - Prof. Feliciano Benvenuti, da Universidade "Cà Foscari";

- O Comitê Interministerial italiano para a programação econômica (CIPE) - M. Carabba-Brunetti Fulvia, do ISPE (Instituto de estudos para a programação econômica -, entidade de pesquisa e análise científica);

- Problemas atuais do orçamento de Estado na Itália - Prof. Salvatore Buscema, da Côrte de Contas e da Universidade de Perusa;

- Tendências na evolução das regiões italianas dotadas de estatuto especial - Prof. Vittorio Ottaviano, da Universidade de Catania;

- As regiões italianas de estatuto comum - prof. Aldo Piras, da Universidade de Perusa;

- As novas tendências na organização das administrações locais na Itália - prof. Giorgio Berti, da Universidade de Ferrara;

- A problemática dos contrôles na Itálla - prof. Aldo Sandulli, da Universidade de Roma;
- Treinamento e Educação dos servidores públicos na Itália - prof. Raffaelle lannotta, Conselheiro de Estado;

- Situação atual da justiça administrativa na Itália - prof. GiovannI Mielle, da Universidade de Florença;

- O Ministério italiano das Participações do Estado e os órgãos de gestão - prof. Giuseppe Guarino, da Universidade de Roma;

- O urbanismo na recente legislação italiana - prof. Federico Spantigati, da Universidade de Roma;

- Administração dos bens culturais na Itália - Michele Cantucci;

- A Lei italiana de reforma hospitalar de 12 de fevereiro de 1968 prof. Giovanni de Cesare, da Universidade de Roma;

- Os problemas de educação na Itália - professôres Carlo Anelli, conselheiro de Estado, da Universidade de Roma, e Domenico Avagliano, da Universidade de Salerno;

- A legislação italiana sôbre os transportes públicos - Alfonso Quaranta, Conselheiro de Estado;

- A organização do turismo italiano - prof. Stelio Valentini da Universidade de Teramo;

- A administração do crédito na Itália - professôres Mario Nigro, da Universidade de Florença, e lole Buccisano;

- A ajuda às zonas subdesenvolvidas na Itália - prof. Giovanni Maregiu, do Centro de formação e de estudos para o Mezzogiorno (FORMEZ) e do Instituto para assistência ao desen- 
volvimento do Mezzogiorno (IASM), Roma;

- A administração da agricultura na Itália - prof. Leopoldo Mazzarolli, da Universidade de Pádua.

Finalmente, convém insistir no lugar comum das vulnerabilidades de uma tradução literal, notadamente no tocante aos assuntos situados no ambito da literatura e das ciências sociais, em face da mobilidade semântica dos têrmos e conceitos utilizados pelos autores, das peculiaridades da terminologia e adequação às condições especificas de cada pais e idioma.

\section{INTRODUÇÃO}

Quando se fala de burocracia, na Itália, o que se tem em vista é um conjunto bastante heterogêneo de pessoal empregado nas diferentes administraçōes públicas. Cogita-se mais precisamente, em particular, do pessoal empregado na administração central e periférica do Estado - pessoa jurídica de direito público. Preliminarmente, cumpre prestar atenção à burocracia do Estado, examinando-se a maneira como ela fol até agora disciplinada, organizada e gerida. A burocracia do Estado representa, de resto, em uma organização administrativa ainda tão fortemente centralizada como a italiana, a parte mais importante, pelo número e pela qualidade do pessoal empregado pelas administraçōes públicas, e serve mesmo como têrmo de comparação e modêlo para quase todo o setor da função pública.

É comum observar-se hoje que a estrutura organizativa do Estado e dos outros órgãos públicos influi diretamente sôbre a maneira pela qual a burocracia é disciplinada, organizada e gerida.

O tipo de administração do pessoal representa, por sua vez, uma condição determinante para a ação e o funcionamento concreto da administração pública de um país. Isto é tanto mais verdadeiro quanto se considera a situação italiana, e mais especialmente o problema da reforma da administração estatal, grave e recorrente que, desde o fim da última guerra, tem conhecido diversas vicissitudes.

Distinguem-se no quadro do problema da reforma administrativa dois aspectos salientes: a) o que se refere à regulamentação e organização das repartiçöes; b) e o outro relativo à administração do pessoal. Êstes dois aspectos são contudo estreitamente interdependentes e se condicionam reciprocamente uin ao outro. Por conseguinte, é quase totalmente ineficaz procurar uma nova formulaçăo para a disciplina de um se, ao mesmo tempo, não se modifica ou altera a disciplina do outro.

\section{O ESTATUTO DO PESSOAL DO ESTADO DE 1957.}

No decurso dos anos de 1954 e seguintes experimentou-se organizar a burocracia de maneira orgânica, independentemente das necessárias modificações das estruturas administrativas nas quais essa burocracia operava.

Os resultados dessa experiência foram objeto do texto único de 1957 que dispôs sôbre os empregados civis do Estado.

Esse texto único impunha uma regulamentação do pessoal administra- 
tivo do Estado no conjunto uniforme e homogêneo porque ela fôra concebida como resultante da relação especial de serviço (ou de emprêgo público) que liga todo funcionário ao detentor da autoridade pública, o Estado (ou a qualquer outro órgão público). Essa legislação regulamentava portanto os modos de constituição, de desempenho e de extinção da relação de emprêgo público, assim como os direitos, deveres e responsabilidades respectivos das duas partes.

As normas de 1957 especificam mais particularmente, na perspectiva Indicada, certos principios expressamente estabelecidos pela Constituição para todos os tipos de serviço público e de emprêgo: a igualdade de acesso de todos os cidadãos aos cargos públicos (art. 51); a obrigatoriedade do concurso público para admissão aos cargos e empregos públicos, excetuados os casos expressamente previstos pela lel (art. 97); o dever impôsto aos que desempenham funções públicas de exercê-las com disciplina e honra, observadas, fielmente, a Constituição $\theta$ as Leis (art. 54), assim como todos os direitos patrimoniais e sociais inerentes à qualidade de cidadăo e à permanente prestação do serviço. Ao lado dêstes princípios de ordem constituclonal outros existem ainda, tradicionais, que servem para especificar a disciplina da relação de emprêgo em face das outras relações de trabalho subordinado: o direito à permanência no serviço ou à estabilidade da relação até o limite da idade prefixada (salvo hipóteses formais de oportunldade verificáveis segundo processos apropriados, ou de delito acarretando a incapacidade para o exercício de um emprêgo público), $\theta$ os principios da hierarquia (com algumas atenuantes quanto ao dever de obediência) e da carreira.

A regulamentação de 1957 - que acabamos de evocar em breves linhas - retomava, ainda que com várias atualizações e aperfeiçoamentos, a apresentação tradicional, comum às demais regulamentações europélas continentais, da relação de emprêgo público. Ela admite um conjunto de garantias em favor dos cidadãos, a propósito da entrada em função, e em favor dos funcionários, quanto ao desempenho da carreira e da permanêncla no emprêgo. Ao mesmo tempo aquela regulamentação considera a posição do funcionário como particular, com relação à da generalidade dos empregados subordinados: ela caracteriza essa posição na base do estado de submissão especial do empregado diante do órgão público. Isso corresponde às duas exigências que se afirmaram progressivamente no século passado e no comêço de nosso século: uma tutela sempre maior da situação dos funcionários do Estado em face das arbitragens possiveis dos responsáveis políticos da administração do Estado, os ministros; um contrôle especial do pessoal preposto às atividades que satisfazem diretamente 0 interêsse público.

O complexo destas garantias e prerrogativas, de direitos e de deveres (o que resumidamente se denomina "Estatuto" ou "estatuto jurídico e econô-

(1) Há além disso dispositivos para determinadas categorias de empregados do Estado (por exemplo, o magistério), que adaptam a regulamentaçăo geral dos empregados da administraçăo civil à natureza da atividade e do serviço prestado por estas categorias de pessoal. 
mico" dos funcionários do Estado), muito acertadamente representou, no plano histórico, uma conquista fundamental para modernlzar a administraçăo pública e hoje constitui, inegàvelmente, um patrimônio indiscutivel da burocracia em geral. Todavia esta situação implica o caráter pretensamente executivo de tôdas as atividades dos empregados públicos, e necessidade de proteger, por um equilibrio adequado de garantias e de contrôles, a execução imparcial do encargo de aplicar e fazer aplicar a lei. Uma abordagem baseada sobretudo na relação de emprêgo público e no reconhecimento implicito do caráter genèricamente executivo das atividades dos funcionários não poderia pois engendrar inovações substanciais em matéria de organizaçăo e de administraçăo de pessoal.

Nesses domínios tentou-se com efeito definir sómente os direitos e deveres recíprocos das duas partes da relação (limitando de um lado as possibilidades de intervenção dos responsáveis políticos e prefigurando, do outro, as expectativas dos empregados), sem satisfazer as necessidades atuais de funcionamento da administração pública como tal.

E isto se fêz em um clima de desconfiança reciproca que contribui para acentuar o movimento das garantias legals em favor da burocracia.

Quanto à organização do pessoal estimou-se poder manter uma rigorosa classificação de todos os empregados, segundo a ordem de importância da formação e das qualificações requeridas, distinguindo-se, para cada administração do Estado, diferentes carrelras e, no Interior de cada uma delas, diferentes graus ou qualificaçőes (baseadas sôbre o critério de uma correspondência entre cada grau ou qualificação e cada função ou responsabilidade; mas êsse critério năo podia ser realmente aplicado).

Limitou-se pois a determinar de maneira aparentemente uniforme a situação das pessoas no interior da escala hierárquica de que faziam parte e a disciplinar as possibilidades de desenvolvimento da carreira de cada um no interior da administração e da carreira à qual pertenciam. As múltiplas pressões dos diferentes grupos interessados, motivados pelas razões de acesso, progressão e melhoria da remuneração, concorreram para dar à classificação um caráter fragmentário e rígido; assim, na maioria dos casos, ela faz abstração da verdadeira natureza das atividades e das tarefas realizadas (decorrendo daí todos os efeltos da disparidade de remuneração que se conhecem). Por outro lado, a administração do pessoal não tem evoluido para formas próprias, segundo caracteres novos; ela permaneceu organizada e regulamentada (salvo as habltuais exceções) como não importa qualquer outra atividade administrativa no quadro do ministério interessado. A administração do pessoal, do ponto de vista funcional, continua a ser assegurada com a ajuda de métodos $e$ processos quase automáticos de seleção e progressão.

Ela aparece também completamente rígida e fragmentária como o tipo de classificação de pessoal sôbre ○ qual se fundamenta, carecendo de uma real ligação $\mathrm{com}$ as atividades a serem executadas. Em geral, pode-se afirmar que não houve jamais uma obra de admi- 
nistração de pessoal real e consciente; o conjunto dos meios utilizados (concursos públicos de admissão, período ou estágio de experiência - estágio probatório - concursos e promoçōes internas, avaliação ou auditoria anual dos serviços prestados, responsabilidade disciplinar), não permitiu senão assegurar uma burocracia sem demérito; não garantiu, no entanto, o prosseguimento de um trabalho positivo de formação e promoção do mérito, das competências e das aptidões, cada vez mais necessárias, à administração do Estado social. Deve-se recordar que o tipo de preparação exigido, tanto para a admissão e engajamento como para a progressão, consiste, sobretudo, em um conhecimento das matérias jurídicas importantes para a administração.

A própria burocracia (principalmente a dos graus superiores através da participação no órgão principal de administração de pessoal de cada ministério ou de cada órgão autônomo, o conselho de administração) terminou por gerar, de maneira discriminatória, os instrumentos de avaliação do pessoal. A rigidez da organização do pessoal reduziu concretamente a mobilidade entre as diferentes carreiras e administrações. $O$ isolamento e o emparedamento do corpo burocrático, determinados pelo sistema de carreiras, entravaram uma osmose apropriada entre - setor público e o setor privado. Enfim, não houve iniciativas adequadas de formação, face ao insucesso da Escola Superior, constituída alguns anos depois que o texto único the previu a organização. Se se acrescenta a isso que o número de funcionários năo fêz senão crescer (até atingir o número de um milhão e meio de unidades nestes últimos tempos), percebe-se que, nestas condições, criou-se fàcilmente uma imponente massa de pessoal dificil de controlar e de gerir, e que ao mesmo tempo espalhou-se um estado geral de insatisfação e mal-estar, tanto no interior da burocracia como no âmbito da opinião pública.

\section{A CRISE DA BUROCRACIA DO}

ESTADO

O Estatuto de 1957 que partia da re. lação de emprêgo público e Implicitamente admitia o modêlo de organização tradicional da administração do Estado revelou-se, no decorrer do tempo, não ser senão uma resposta parcial e, sob certos aspectos, metodològicamente incorreta, ao problema da reforma da burocracia. E, sobretudo, não impediu a ocorrência de um estado de mal-estar geral que se pode definir, em síntese, como uma crise de responsabilidades. A organização do pessoal, fundada sôbre critérios de progressão hierárquica pessoal, năo podia ter por correspondente uma organização das repartições atribuindo conteúdos diversos às múltiplas qualificações individuais, se bem que se efetivaram tentativas nesse sentido para as carreiras dos quadros e para certos ministérios. Contudo, resta ainda demonstrar o quanto é possível e útil se apolar sôbre as qualificações do pessoal para reorganizar as repartições.

Por sua vez, a administração de pessoal baseada em mecanismos vazios de credibilidade real em matéria de avaliação do mérito (como a jurisprudência do Conselho de Estado acabou eventualmente por admiti-lo) não favorece senão fracamente o engajamento pessoal dos funcionários. 
A opinião pública estimou dever imputar à burocracia o insatisfacório desempenho da ação administrativa; mas, por sua vez, a burocracia, sobretudo nas camadas mais sensíveis, julgou estar privada das competências e atribuições necessárias à execução responsável dos seus encargos.

Assim se fazia pela necessidade de rever a situação genèricamente executiva das atividades dos funcionários, e a estrutura monocrática e hierárquica dos ministérios, a fim de reorganizar os serviços sôbre uma base meIhor articulada e diferenciada. Encarou-se, então, a necessidade de abordagem completa e orgânica do problema da reforma burocrática que centralizasse a obra de reforma, antes de tudo, no tocante à reorganização das repartições e dos processos para, em seguida, extrair-Ihes as conseqüências apropriadas e aplicá-las sob a forma de uma melhor classificação de pessoal.

O principal fim para o qual tende a obra da reforma conjunta da administração e da burocracia tornou-se, pois, a identificaçăo de um tipo de organização funcional para cada ministério ou órgão autônomo.

Cogita-se de proceder em seguida a uma vasta desconcentração, tanto nos niveis centrais, como nos periféricos, em favor dos chefes dos serviços dos ministérios e restabelecer, além disso, o equilibrio rompido entre as tarefas efetivamente realizadas $e$ as qualificações possuídas.

Deseja-se substancialmente construir não uma burocracia disciplinada e ordenada de maneira monolítica (o que provocou sua irresponsabilidade prática), mas - por assim dizer tantas burocracias quantas existam formalmente oriundas dos principais tipos das atividades administrativas existentes e necessárias.

O que não quer dizer que se deva fragmentar a unidade fundamental da regulamentação do pessoal porque ela está, ao contrário, progressivamente integrada no direito mais amplo de todos os trabalhadores (como o demonstra, por exemplo, a extensão explicita das liberdades sindicais aos funcionários civis).

Trata-se antes de isolar do problema do estatuto do pessoal o problema de sua organização especifica, setor por setor, e o das políticas e iniciativas a adotar para seleção, a formação $\theta$ a utilização, em geral, do pessoal.

\section{A REFORMA DA BUROCRACIA DO ESTADO}

Tais são os problemas que duas importantes leis de 1968 e de 1970 referentes à reforma da administração da burocracia do Estado ${ }^{2}$ tentam resolver.

Estas leis são estreitamente ligadas à constituição, sôbre todo o território nacional, das regiões, entendidas como

(2) Trata-se de duas leis de delegaçăo legislativa do Parlamento ao govérno. A lei de 1968 lançou as bases da reforma, mas năo fol concretizada, vencidos os prazos previstos. A lel seguinte, de 1970 , prorrogou os prazos de exercicio da delegação completando e aperfeiçoando a situaçăo fixada pela lei precedente. As duas leis deverăo ser agora aplicadas de maneira especifica, por meio de um importante conjunto de decretos legislativos a promulgar, em diferentes épocas, nos dois anos vindouros. Os primeiros foram publicados em fins de 1970; é cedo para avaliá-los. 
órgãos políticos autônomos dotados de um vasto elenco de atribuiçőes administrativas (além de suas atribuições legislativas), no exercício das quais deverão substituir os órgãos centrais $\mathrm{e}$ periféricos do Estado.

A reforma supõe, contudo, uma considerável redução de repartições e do pessoal do Estado, em conseqüência da transferência ou da delegação de funçōes às regiöes; ela prevê, além disso, uma modificação paralela do papel e das atribuições reservadas à administração central do Estado, entre outras, em virtude da vasta delegação de competências da administração ativa estabelecida em favor dos órgãos periféricos que o Estado deverá conservar.

Em conseqüência da radical renovação das estruturas administrativas, as duas leis de reforma prevêem profundas modificaçöes na organização e na administração da burocracia. Antes de tudo é preciso acentuar que a reorganização dos órgãos centrais e periféricos do Estado não sòmente se afasta das concepções tradicionais da carreira, mas, ainda, pressupöe a criação, no seio da função pública superior, de um nôvo corpo de altos dirigentes.

Prevê-se, de uma maneira geral, em conseqüência, a redução das atuais qualificações existentes em tôdas as carreiras e a adoção de qualificaçōes rigorosamente correspondentes às diversas atribuições e responsabilidades. A êste respeito é preciso notar que a progressão barêmica da retribuição pessoal é assegurada na mesma qualificação, independentemente da progressão de uma qualificação à outra; assim, a preocupação de melhorar a remuneração influenciará cada vez menos a seleção adequada do pessoal para as qualificações superiores.

Sôbre a base das qualificações assim estabelecidas preparou-se, de outro lado, uma escala de remuneração unitária que assegurou uma retribuição igual para serviços iguais ou equivalentes entre as diversas qualificações.

A inovação mais significativa, em matéria de organização do pessoal, diz respeito, todavia, aos funcionários dirigentes, mais precisamente os três graus mais elevados da carreira de direção atual.

Admitindo-se que os principais serviços centrais e periféricos devem ser transformados de simples divisões internas dos ministérios em órgãos exteriores da administração, a lei de reforma prescreveu que as competênclas e as responsabilidades dos chefes dêsses serviços serão regulamentadas de uma maneira nova e autônoma.

Ela tenta igualmente dessa maneira atenuar a crise de responsabilidades que se tornou uma das caracteristicas da burocracia, transformando, ao menos nos setores superiores, 0 antigo modêlo hierárquico e legalista da burocracia em uma organização baseada sôbre a responsabilidade pessoal e profissional dos funcionários (recordarse-á, a êste respeito, que para as carreiras de pessoal técnico prevêemse igualmente qualificações profissionais).

Prevendo esferas autônomas de competência e atribuindo-selhes responsabillidades especiais espera-se lançar as bases da criação de quadros efetuando um equilíbrio mais satisfatório entre as estruturas e as tarefas adminis- 
trativas do Estado. Em particular, aquêles aos quais serão atribuidas funções de direção, segundo o esquema previsto, serão responsáveis "tanto pelo cumprimento das diretivas políticoadministrativas emanando do govêrno como pela rigorosa observância dos procedimentos legais e regulamentares, e pela obtenção dos resultados".

Essa disposição - além de outras - da lel de reforma de 1970 determina, sem sombra de dúvida, um primeiro efeito importante de rutura com a precedente uniformidade de organização e experimenta diferenciar as situações do pessoal em função do tipo de tarefa e da responsabilidade assumida. Lembrar-se-á, a respeito, a outra importante Inovação da mesma lei, segundo a qual as tarefas e a remuneração dos empregados de tôdas as carreiras (salvo a dos quadros) e dos operários, poderão ser fixadas por contrato coletivo enquanto que a lei se reserva o direito de regulamentar tudo quanto se refira ao pessoal de direção.

A nova disciplina dos dirigentes comporta também uma tomada de consciência pela alta burocracia interessada, de suas responsabilidades diretas.

A criação de uma classe de quadros superiores que, por fôrça de sua preparação e mentalidade, estão em condições de corresponder ao que delas aguarda a lei de reforma, é contudo deixada aos novos sistemas de formação e seleção do pessoal, sobretudo os que determinarão 0 acesso aos cargos e funções de direçăo. Previu-se com efeito, nesse sentido, a reorganização da Escola Superior de Administração Pública que deveria poder funcionar segundo os projetos em estudo, de maneira semelhante à da Escola Nacional de Administração francesa.

Depois dos dois primeiros anos de estudos universitários, os estudantes poderão ser admitidos, mediante concurso, a um curso de formação e seleção de funcionários dirigentes da administração pública. Êste curso terá a duração de dois anos. A frequeêncla do curso permitirá, ao mesmo tempo, completar os estudos preliminares $\theta$ a inscrição aos cargos com uma adequada preparação nas ciênclas $\theta$ nas técnicas hoje indispensáveis à profissão administrativa. Por sua vez, os funcionários do quadro superior que seguirem um curso de formaçăo (com exames finais), de duração não inferior a um ano, poderão ter acesso às qualificações superiores de dirigentes. Durante o curso, os candidatos serăo enviados às administrações diferentes daquelas de que são provenientes ou encaminhados às grandes emprêsas, públicas ou privadas, a fim de estudarIhes a organização.

A lei de reforma prevê ainda outras inovações em matéria de administração de pessoal que não podemos aquil senão mencionar ràpidamente. Algumas dessas inovações são destinadas a aumentar a competitividade para o acesso ao emprêgo público com relação ao emprêgo privado: simplificação e redução dos prazos nos processos de concurso; unlficação dos concursos para várias administraçóes; transformação dos concursos para 0 pessoal técnico; medidas particulares concernentes às remunerações. Outras inovações interessam uma melhor seleção e utilização do pessoal em ser- 
viço, graças às margens mais amplas de mobilidade: a unificação das funções no interior da mesma administração; a facilidade de intercâmbio ou passagem entre administrações e entre carreiras; a instauração de novos critérios de avaliação para a promoção com a finalidade de selecionar o pessoal; garantias em favor do emprêgo do pessoal técnico nas tarefas técnicas e científicas; enfim, disposiçöes facilitando a passagem das administraçōes do Estado às novas administrações regionais.

Como fàcilmente se verificará, graças a algumas indicações de reforma menclonadas, trata-se de um conjunto bastante vasto de modificações que se espera operar na estrutura viva da burocracia existente. É nesta perspectiva que é preciso julgar também os limites da reforma: é preciso relembrar, com efeito, a dificuldade intrínseca de obter resultados que conduzam a uma radical renovação.

A burocracia é constituida de um corpo fracamente permeável às inovações e através das pressões sindicais e políticas ela se opõe, muitas vêzes, às tentativas de reforma, ou tenta, internamente, privá-las de sua significação. $O$ conjunto das medidas adotadas pelas últimas leis de reforma ainda carece, por vêzes, de coragem, e quiçá de precisão: seria preciso julgar a rigidez e o caráter fragmentário das estruturas e dos instrumentos de administração de pessoal, e sem perder de vista os limites reais de receptividade dos interessados. De uma reforma assim situada surgirá, provàvelmente, uma burocracia ainda mais forte, mas - espera-se - , igualmente melhor estruturada e mais fàcilmente controlável.

E' preciso relembrar nesse sentido que a lei de 1970 prevê para o Presidente do Conselho a obrigação de apresentar cada ano ao Parlamento "um relatório sôbre o estado da administração pública, ao mesmo tempo que o organograma analítico e de conjunto de cada administração particular".

Consoante êste dispositivo, a pessoa do Presidente do Conselho aparece ainda mais como o centro de govêrno da burocracia do Estado: tratar-se-la, contudo, de proporcionar à Presidência do Conselho as estruturas e os podêres apropriados para uma política orgânica da função pública.

\section{O PESSOAL DOS OUTROS ÓRGÃOS PÚBLICOS}

Assim como a burocracia do Estado atravessa hoje uma fase de transição, da mesma forma as condições do pessoal das regiões, das administrações locais e dos outros órgãos públicos, estão sujeitas a uma intensa obra de reorganização e de revisão crítica.

o pessoal empregado nas demais administrações públicas, além das especificamente estatais, rege-se por uma grande diversidade de leis $\theta$ de regulamentos correlacionados com a diversidade dos órgãos públicos.

Existem contudo certos princípios constitucionais já mencionados, aplicáveis a todos os agentes da função pública, independentemente do órgão ao qual pertencem.

A lei do Estado, outrossim, dispondo sôbre a organização dos diferentes ór- 
gãos ou das diferentes categorias de órgãos homogêneos, tem freqüentemente estabelecido as características fundamentais da relação de serviço, deixando, se fôr o caso, à capacidado de auto-organização de cada órgão a tarefa de completar as disposições impostas.

Mais recentemente, verificou-se o fortalecimento da tendência para ampliar (por meio dos mais diversos artificios) a regulamentação particular dos funcionários civis do Estado ao pessoal dos outros órgãos públicos, inclusive os órgãos dotados de autonomia legislativa na matéria (como as regiões) e os outros órgãos territoriais autônomos (como as províncias e as comunas). As instituições características da burocracia do Estado tornaram-se, em outro sentido, princípios tradicionais do emprêgo público, salvo exceções expressas encaradas paulatinamente pelas leis (como ocorreu, em geral, com os órgãos econômicos públicos que puderam adotar formas de gestão e de direção de pessoal análogas às das emprêsas privadas).

Se bem que várias leis recentes puderam fazer referência impondo critérios para a regulamentação do pessoal de categorias particulares de organismos, aos "princípios das leis em vigor regendo a relação de emprêgo público", isto é, aos principios do emprêgo público do Estado, como a estabilidade, a carreira e a hierarquia.

A progressiva uniformidade do estatuto dos funcionários públicos em geral, sobretudo quando comparado com as normas heterogêneas de outrora, apresenta aspectos positivos: ela se liga à necessidade de igualizar as condições jurídicas $\theta$ econômicas de todos os trabalhadores.

A tendência à uniformidade encontra-se, de resto, ainda agora em fase de desenvolvimento e de aperfeiçoamento: reflita-se na recente unificação da regulamentação para o pessoal dos hospitais e na unificação proposta das normas referentes ao pessoal dos órgãos públicos dependentes do Estado (com exclusão dos organismos economicos).

A uniformidade de remuneraçăo, por outro lado, evidenciou-se um obstáculo perigoso ao desenvolvimento autônomo e eficiente das diferentes administrações públicas quando compreendida como extensão mecânica dos critérios de organização e de administração de pessoal em vigor na administração do Estado.

E o que ocorreu demasiado freqüentemente na Itália à margem do respeito pela variedade real das atlvidades $e$ dos encargos realizados nas regiőes, nos órgãos locais e outros organismos públicos. Em particular, nas cinco regiöes de estatuto especial, verificouse a transposição por diferentes razöes do modêlo da burocracia do Estado, sem nenhuma possibilidade de experimentar novas formas de organização do trabalho e do pessoal; a consequaencia fol que se reproduziram as principais irregularidades de funcionamento que se busca hoje eliminar ou conter, no Estado.

Nas provincias e nas comunas igualmente fêz-se penetrar o tipo de organização burocrática do Estado: em virtude de normas datando de antes da guerra, o principal funcionário dêsses 
organismos (o secretário-geral) liga-se ao Estado por uma relação de serviço; além disso, a reprodução para todo 0 . pessoal local dos modelos de organização em vigor para o Estado se impôs através do contrôle por êste presentemente exercido até agora sôbre as regulamentações locais.

Compreende-se, pois, que as regiöes tentem hoje derrubar os principais Iimites que a lel estatal levanta em matéria de pessoal e pretendam lançar uma nova organização de tipo profissional, de caráter horizontal, baseada sóbre grupos de trabalho. Neste sentido é que vão os princípios contidos nos estatutos das regiões ordinárias (até o presente ùnicamente deliberados pelos conselhos regionais) e alguns projetos de reformas de regiōes especlais (Sicilia, Sardenha). Em sua pesquisa dos meios próprios para assegurar a responsabilidade profissional e pessoal dos funcionários, certos estatutos das regiões ordinárias prevêem também empregar relações de trabaIho limitadas no tempo, ultrapassando os principios tradicionais da carreira e da estabilidade. Algumas destas proposições renovadoras fracassaram, grande parte do pessoal das novas regiōes será transferido das adminis- trações do Estado e deverá, por conseguinte, ser organizada e gerida de maneira a respeitar a situação adquirida na administração de onde se orlginam.

No concernente às províncias e às comunas, é preciso assinalar vários projetos e iniciativas para reorganizar, de maneira autônoma, o pessoal pelo método da "job evaluation"; ao mesmo tempo fixaram-se as condiçőes econômicas do pessoal por contrato coletivo, em bases nacionais. Para os outros organismos públicos dependentes do Estado, deve-se aguardar a provável adaptação de sua organização à legislação regional: o problema do regime de pessoal dêsses organismos se relaciona pois ao do pessoal regional ou, em outras palavras, ao problema de constituir esquemas de organizações e de remuneração do pessoal, sempre apoiados no contrato coletivo, para cada grupo de órgãos homogêneos em estreita relação com a natureza das tarefas realizadas. "CDU 35081 (45)"

- Revue Internationale des Sciences Administratives, Volume XXXVII, 1971.

- Nọ 1-2, p. 52/53. - IIAS, Bruxelles, Belgique. 